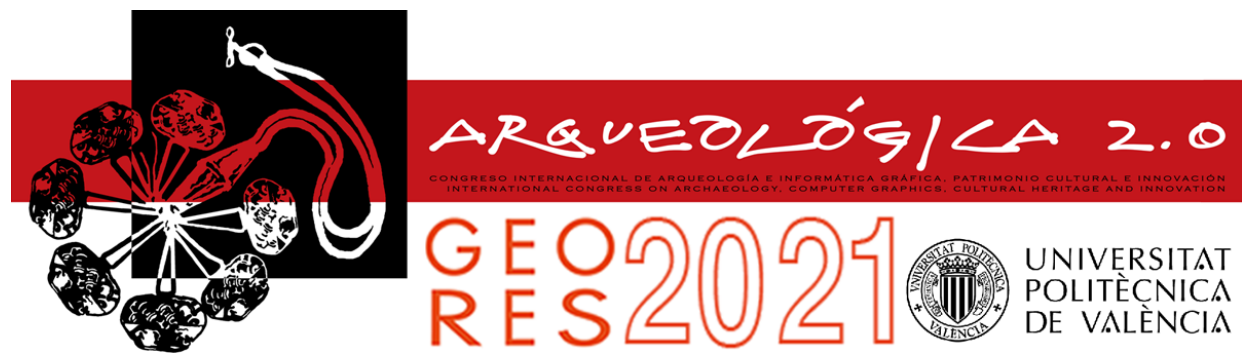

Proceedings of the joint international event $9^{\text {th }}$ ARQUEOLÓGICA

$2.0 \& 3^{\text {rd }}$ GEORES

Valencia (Spain).

26-28 April 2021

\title{
BIM INTEROPERABILITY: OPEN BIM-BASED WORKFLOW FOR HERITAGE BUILDING INFORMATION MODELLING (HBIM). A MULTIDISCIPLINARY APPROACH BASED ON ADVANCED 3D TOOLS AND EXCHANGE FORMATS
}

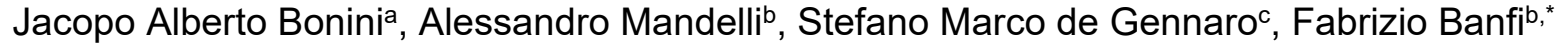 \\ ${ }^{a}$ AB Studio Archiettura, 20156 Milan, Italy. j.bonini@abstudioarchitettura.it \\ ${ }^{\mathrm{b}}$ Department of Architecture, Built Environment and Construction Engineering (DABC), Politecnico di Milano, Piazza Leonardo da Vinci \\ 32, 20133 Milan, Italy. fabrizio.banfi@polimi.it; alessandro.mandelli@polimi.it \\ c Politecnico di Milano, Piazza Leonardo da Vinci 32, 20133 Milan, Italy. stefanomarco.degennaro@mail.polimi.it
}

\begin{abstract}
:
In recent years we have witnessed how technology applied to built heritage has exponentially changed the daily practices of the various experts involved in the life cycle of buildings. The techniques of representation of historical architecture have been able to make use of new 3D survey tools as well as research methods capable of managing a large amount of data while improving the level of information (LOI) and accuracy of the surveyed artefacts. On the other hand, professionals still must make use of many exchange formats to share their digital representations (3D, 2D) and analysis. For this reason, this paper describes the research approach followed to obtain "standard" architectural representations of a heritage building in the Cultural Heritage domain. The word "standard" is used in its original meaning: "something established by authority, custom, or general consent as a model or example" (Collins Dictionary). In this context, 3D models have a primary role in the workflow because their position is in-between the 3D survey techniques that come first and the restoration/maintenance activities. The authors' thought is that the workflow should be as smooth and sustainable as possible to have an effective standardization and collaboration among disciplines, sectors and technicians working in the different study areas.
\end{abstract}

Keywords: interoperability, Building Information Modelling (BIM), exchange formats, IFC, 3D reconstruction, laser-scanner survey, photogrammetry

\section{The era of standardization and BIM interoperability}

In the last decades, there was an increasing use of 3D instruments and technologies to survey, model and spread any kind of 3D real object, from artefacts, artworks, buildings, and landscapes. At the same time, government bodies have implemented, and where possible made mandatory, new standards capable of communicating the levels of development, detail (LOD) and information (LOI) of digital models. Many nations have encouraged and subsequently adopted new supranational standards such as the ISO and CEN to guarantee the quality of those new types of digital representations (Luedy, Couto, Silva \& Hormigo, 2020). As we well know, in December 2018, ISO 19650 was adopted, which through the mechanism of direct adoption of the Vienna Agreement became a European (EN) and national standard for each member state in 2019. Accordingly, the standard should therefore represent the state of the art, practice and science shared by all stakeholders (private and public), concerning a specific process, service, or product. In this context, interesting studies have identified the main shortcomings of these guidelines oriented to new buildings and proposed their methods able to improve HBIM projects (Banfi, 2020; Tommasi \& Achille, 2017).

Furthermore, for most of the member states of the European Union where BIM is not yet mandatory, there is an urgent need to integrate the scan-to-BIM process into guidelines and standards to improve and better specify LODs and LOls of built heritage. Historical buildings are characterized by complex and unique elements of their kind, difficult to obtain from a customization process of object libraries already included in BIM platforms such as Autodesk Revit and Graphisoft Archicad.

The added value of these methods was the integration of survey tools capable of improving the three-dimensional representation of digital models moving from simple

"Corresponding Author: Fabrizio Banfi, fabrizio.banfi@polimi.it 
points to accurate informative models. Thanks to in-depth analysis and study of application cases that have obtained tangible feedbacks (Brumana et al., 2018; Cabrelles, Blanco-Pons, Carrión-Ruiz, \& Lerma, 2018; Tucci et al., 2019), it emerged that the correct creation of complex models mainly depended on four factors:

1) accurate digital surveys based on the most modern 3D survey tools and historical documentation (data collection);

2) an appropriate three-dimensional representation of the buildings surveyed (model generation - scan-toBIM process);

3) information mapping and parameter definition of BIM objects;

4) sharing of information previously mapped in the BIM models.

Nevertheless, often the results and outcomes of these works are caged in their proprietary formats and the results are editable, visible, updatable, and upgradable only if users have the software that produced that files. Moreover, there is the risk of the obsolesce of the files, it happens that the software is discontinued or no more compatible with new operative systems. Last, in collaborative projects between different actors and disciplines, there is often the possibility that the files are not compatible between different application, i.e., structural or energy software may not correctly read the proprieties of the model generated using the $3^{\text {rd }}$ program.

In this scenario, in 2013 the IFC was ISO certified. Even if IFC is commonly referred to as an exchange format, it is a schema. IFC was developed by buildingSMART which is a worldwide industry body driving the digital transformation or the built asset industry buildingSMART is committed to delivering improvement by the creation and adoption of open, international standards and solutions for infrastructure and buildings. buildingSMART is the community for visionaries working to transform the design, construction, operation, and maintenance of built assets. buildingSMART is an open, neutral, and international not-for-profit organization. (buildingSMART, 2020). IFC born mainly for designing, planning, and building new constructions; a typical workflow with IFC is the following: an architect designs its project and export in IFC, the engineer imports the IFC in its software where he can design all the systems (electrical, hydraulic, ventilation, etc.), he can perform structural and energy analyses, he can manage the timesheet of the works. The IFC transport enough information for the simulation software to read and analyse the IFC spaces in the referenced model. If a change is needed, the engineer should not modify the IFC, but he needs to ask who designed the building to make the changes and deliver again the IFC

If this is true for the new construction, this is not always possible if we are dealing with Cultural Heritage, where the objects already exist. In this field, the geometries involved in the modelling phase are quite complex and often they are not classifiable into predefined architectonical classes managed by 3D modelling BIM software (Tommasi, Achille, \& Fassi, 2016). In this case, it is fundamental to manage the whole process verifying and testing the interoperability between applications, starting from the survey until the management of the final
3D model (Banfi, 2017). In the case study here presented, the applications involved in the process are Leica Cyclone, Agisoft Metashape, Autodesk Recap Pro, McNeel Rhinoceros, Autodesk Revit, Unreal Engine, and a BIM-based cloud platform. The integration between these domains and the complementary nature of the information provided by each technology could, therefore, lead to having a new data flow and a highly detailed and holistic picture of a project (Colucci, De Ruvo, Lingua, Matrone, \& Rizzo, 2020; Goulding, Rahimian \& Wang 2014).

\section{The Senate Building in Milan and research objectives}

The case study is represented by the Senate building in Milan currently home to the State Archives. The method described in the article regards the most representative part of the construction, i.e., the main façade designed by Francesco Maria Richini in 1632 among the major protagonist of the seventeenth-century Milanese architectural scene (Fig. 1). The façade is about $50 \mathrm{~m}$ long and $18 \mathrm{~m}$ high built in the baroque style. The central part, where the main access is, has a semi-elliptical shape, the windows are on two rows decorated with curved and triangular tympanums.

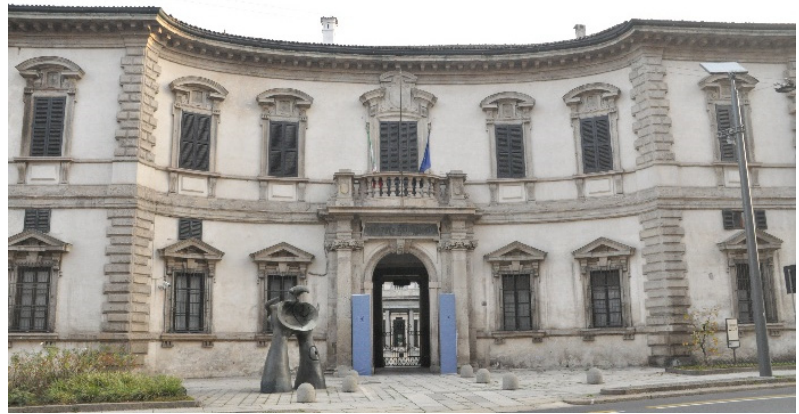

(a)

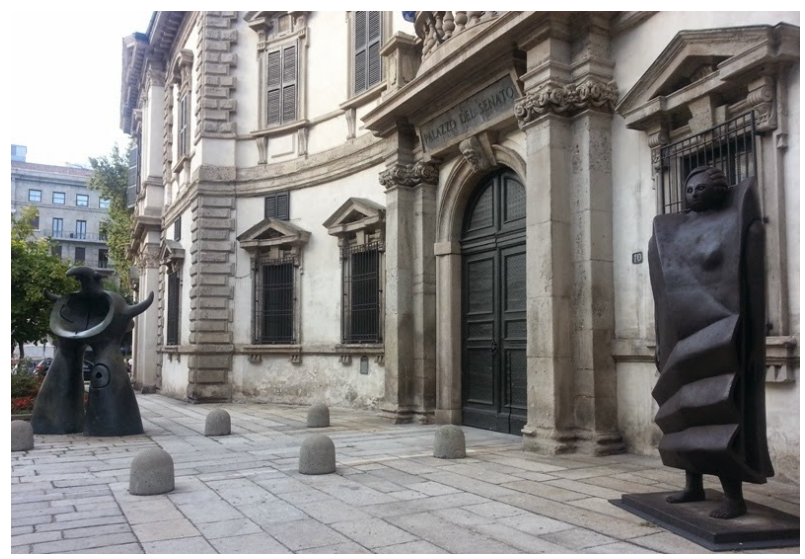

(b)

Figure 1: The main façade of Senate building (a), via Senato 10 , Milan and the architectural details of the entrance (b).

The building was built starting in 1608 by the will of Archbishop Carlo Borromeo as the seat of the Helvetic College, an institution he founded in Milan in 1579 to train the Swiss clergy engaged in the fight against the Protestant reform. It originally overlooked the internal canal that ran along the current route of the ring road 
known as the "circle of canals", buried since 1929. The bronze statue that can be seen in front of the entrance is one of the last works of Mirò, the memory of the Mirò Milano exhibition in 1981. Over the decades, the project was assigned to different foremen including Cesare Arano, Aurelio Trezzi, Fabio Mangone (master builder of the Milan Cathedral) and then resumed around by Francesco Maria Richini in 1632. Richini had to deal with a problem that was not easy to solve: if the façade had been aligned with the internal courtyards, it would not have been parallel to the Naviglio, while the façade of the church was. The original solution found by the architect was that of the concave façade (Fig. 2), devoid of architectural orders, which "partially hides the lack of alignment with the court" (Onida, 1997). Since the Litta coat of arms can be seen on the façade, it can be said that this was not completed until after 1652 during the episcopate of Alfonso Litta.

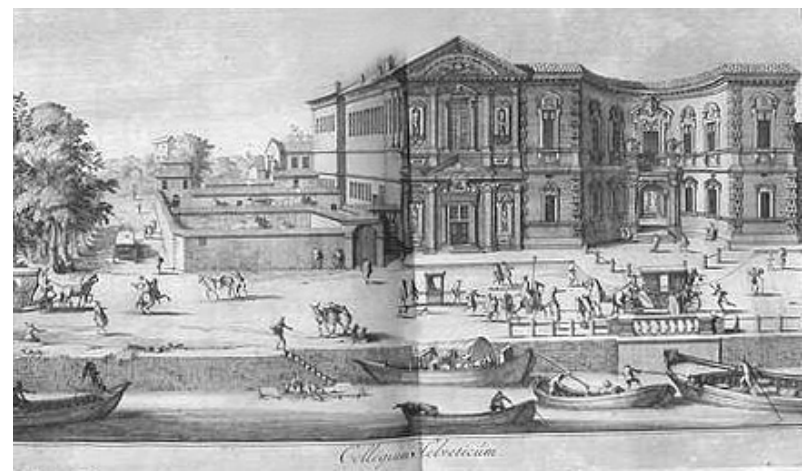

Figure 2: The main façade of the building. Civica Raccolta delle Stampe Achille Bertarelli.

Over the centuries the building had a troubled historychanging often function and became the seat in 1786 of the Supreme Governing Council, the seat of the Lower Chamber (Consiglio de' Juniori) of the new-born Cisalpine Republic in 1797, the seat of the Ministry of the Italian Republic first in 1802, and then of the Kingdom of Italy. From 1809 to 1814 it was used as Palazzo del Senato (hence the name by which the building is known) and from 1817 to 1859 it was the seat of the State Accounting. It should also be remembered, in 1329 Azzone Visconti promoted the strengthening of the city walls and had the moats dredged, thus creating the Cerchia dei Navigli and making Milan a very rich city, thanks to the trade made possible by these waterways. The relationship between canals and the buildings remained unchanged over the centuries, representing a real asset for its representative functions and essential services for the city of Milan (Fig. $3)$.

Thanks to a long work that ended in 1886, all the archives previously deposited in various city locations were transferred to the building and the current State Archives of Milan was born. Between 12 and 13 July 1943, the Senate building was affected by the bombings of the Second World War (Fig. 4). In August 1943, during the devastating bombings on Milan, the building suffered extensive damage both in the wall structure and in the preserved documentation. Regarding the first and related reconstruction works "the criterion of saving the façade and the courtyards and of reconstructing the rear buildings according to utilitarian criteria was followed" (Onida, 1997).

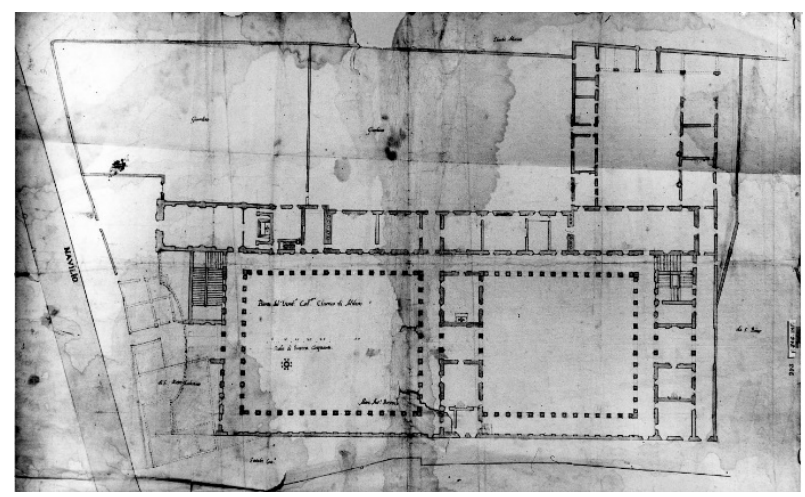

Figure 3: Historical drawings by Marcantonio Banuci: Ground plan of the Collegio Elvetico with the canal marked on the left side. Inventory-Catalogue of the Drawings in the Biblioteca Ambrosiana.

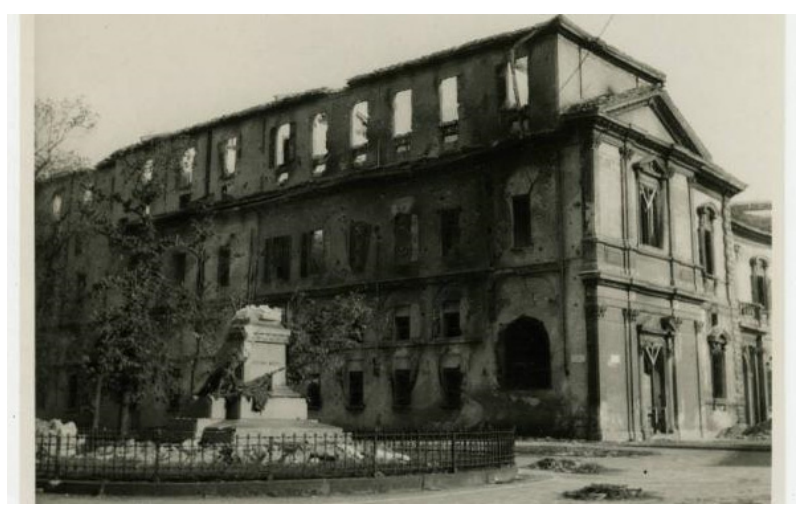

Figure 4: Bombings 1943 - Outside at the corner of via Senato and via Marina. S.A. Dotti \& Bernini.

As shown in Figure 5, the building was severely hit in the raid of the night from 14 to 15 August 1943 by four bombs. Starting from the end of the war, the building underwent an architectural reconstruction that lasted for most of the 1950s and was entrusted to the Superintendency. In March 2008, a vast campaign of stratigraphic investigations was conducted in some rooms of the former offices of the Superintendence for archival assets. The analyses that highlighted the most interesting results are those that were carried out in the internal rooms. In the latter, a vaulted brick structure was found entirely decorated with ornaments on an ochre background. Below this decoration in lean tempera, analyses have brought to light an even older decoration, again with motifs, painted with lime on a blue-blue background. Following the findings, it was decided to proceed in 2009 with the urgent restoration of the ancient pictorial finishes dating back to the mid-century XVII by the Superintendence for Architectural Heritage of Milan and D\&A Communication SRL of Rome (Paola Villa, ND).

Today the façade of the building arrives at us in fair condition. Its historical and cultural heritage represents one of the main architectural assets of the city of Milan.

In recent years, the author's scientific research activity has shown how different methods and technologies of the latest generation oriented to heritage documentation can support 3D survey, digital architectural representation and restoration and maintenance activities. For those reasons, this study proposes a multidisciplinary approach based on the use of the most advanced $3 D$ tools and 
exchange formats (proprietary and open) oriented to represent and share the tangible and intangible values of the built heritage. In particular, the proposed method aims to lay the foundations for a holistic approach based on the integration of different survey tools, software applications, research methods, architectural representations and above all characterized by high levels of interoperability.

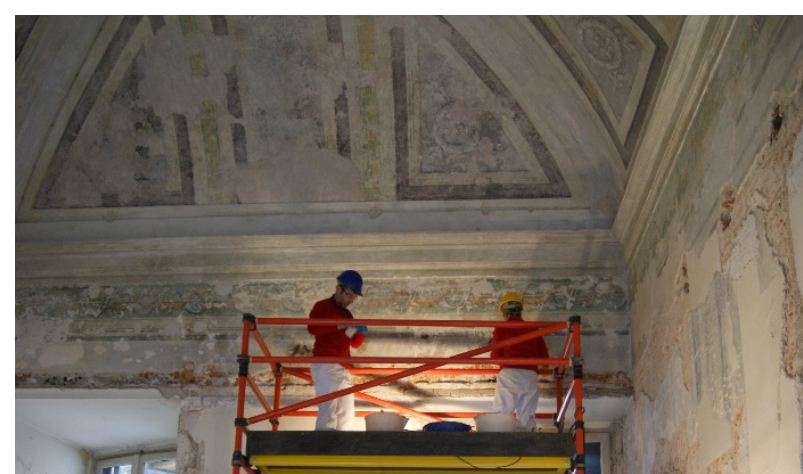

Figure 5: Conservative restoration performed on the decorative apparatus of the "room of frescoes". Source: "Milano nei cantieri dell'arte". Photographs by Alberto Favara / Villa Archive.

Figure 6 shows the high number that a professional must be able to convert and above all optimize to create an appropriate scan-to-BIM process. As briefly anticipated, the large number of formats and software leads to a high loss of information both of a geometric and descriptive/informative nature. For this reason, one of the main results of this study is also to define a data flow that is as sustainable as possible, proposing:

1) the most updated version regarding the interoperability of exchange formats for the generation of HBIM models;

2) transform information and point clouds from proprietary formats to open BIM models.

\section{3) 3D geometrical survey of the Senate building}

As widely discussed, (Achille et al., 2019) nowadays in standard conditions the use of photogrammetry or laser scanner to get the 3D information is almost the same. This is true both for simple and complex objects. Nevertheless, several factors influence the choice of one technique or the other.

In the professional activity, the first parameter that rules the choice is the cost of the instrument, even if the gap between camera plus lenses and terrestrial laser scanners is getting smaller year after year.

Nowadays, also the portability of the instruments is almost the same. In some cases, the laser scanners are more compact than cameras, such as the Leica RTC or Leica BLK360.

Today, the real difference between the use of photogrammetry or laser scanner lies in the elaboration phase and the needs of the project manager. On one hand, both the use of the laser scanner on the field and the following data elaboration is almost straightforward. With the latest technologies, theoretically, the use of the markers is no more needed for the registration of the clouds. A very accurate pre-registration is automatically done during the survey campaign. During the data elaboration, the operator must check the preliminary result of the alignment and locally correct the possible misalignments.

\section{IMPORT/EXPORT POINTCLOUD FORMATS}

Faro, Scene:

Import: XYZ, CVS, COR

Export: PTC, PTX, PST, XYZ, DXF, IGES, VRML, E57 Autodesk, ReCap:

Import: ASC, CL3, CLR, E57, FLS, FWS, ISPROJ, LAS, PCG, PTG,

PTS, PTX, RDS, TXT, XYB, XYZ, ZFS, ZFPRJ, DXF, DWG

Export: RCS, RCP, PCG, PTS, E57, DXF, DWG Bentley, Pointools:

Import: POD, OBJ, SHP, DXF, DWG, ESRI, E57, ZFS, LAZ, LAS,

FLS, FWS, XYZ, PTS, PTX, PTZ, TXT, LWO, CL3, BIN, RSP, 3DD Export: POD, PTS, XYZ

Capturing Reality, RealityCapture

Import: JPG, PNG, PTX, E57

Export: OBJ, PLY, XYZ, DSM

Leica, Cyclone:

Import: XYZ, PTS, PTX, LAS, E57, ZFS, DP, LSPROJ, BLK

Export: XYZ, PTS, PTX, E57, DXF, PCI/CWF, DBX, XML, RCP, RCS Trimble, Realworks

Import: XYZ, E57, LAS, LAZ, ZFS, RSP, FLS, DP, PTX, PTS Export: E57, ASC, LAS 1.2, LAS 1.4, LAZ,

POD, PTS, PTX, TZF, BSF, KMZ, DWG, DXF, DGN, FBX, OBJ Agisoft Metashape

Import: JPG, PNG, OBJ, PLY, LAS, LAZ, E57, PTS, PTX, PCD

Export: OBJ, PLY, TXT, LAS, LAZ, E57, CL3, PTS, DXF, U3D, OC3

\section{D EXCHANGE FORMATS}

3DM, 3DS, ASM, CAM360, CATPART, CATPRODUCT, CGR, DAE, DLV3, DWF, DWFX, DWG, DWT, EXP, F3D, FBX, GBXML, IAM,

IDW, IFC, IGE, IGES, IGS, IPT, JT, MODEL, NEU, NWC, NWD, OBJ, PRT, RVT, SAB, SAT, SESSION, SKP, SLDASM, SLDPRT, SMB, SMT, STE, STEP, STL, STLA, STLB, STP, WIRE, X B, X T, XAS, XPR

Figure 6: The huge number of exchange formats that a professional must consider approaching a scan-to-BIM project.

On the other hand, the photogrammetric approach requires skilled operators both in the acquisition phase and the elaboration too. The images must be as much as possible sharp, not blurred, possibly with the same illumination without strong shadows. The geometry of acquisition must follow precise rules of position and overlap (Grussenmeyer, Hanke, \& Streilein, 2002). The use of known points, i.e., high precisely measured markers, or architectonic points is mandatory to get the correct result in the elaboration phase.

The choice of using photogrammetry is usually due to the need for high-resolution textures, to produce orthophotos. This is possible also with laser scanners since some of them have an integrated camera, but the quality is not comparable with cameras, in terms of resolution. Another option is to use ad hoc cameras or supports for professional cameras, that placed in the same position of each scanner station, which gives the possibility to reproject the colours and textures on the laser scanners point clouds and meshes.

In the case study here presented, having at disposal both a Leica BLK360 and a consumer camera, it was chosen to use both techniques to have both the precision given by the laser survey and the high-quality textures coming from photogrammetry.

The acquisition of the geometries was performed by using Leica instruments, namely the total station TS12 to 
measure the topographic network and some architectonic points, and the BLK 360 to get the dense point cloud. The architectonic points were useful to double-check in Cyclone the automatic alignment performed via tablet during the survey campaign.

\subsection{Laser scanner survey}

The laser was placed on its tripod at a horizontal distance of $10 \mathrm{~m}$ from the façade, it was necessary to acquire the data from three different stations to get the geometry of the building. One of these scans was acquired from a farther point go get also the slope of the roof (Fig. 7).

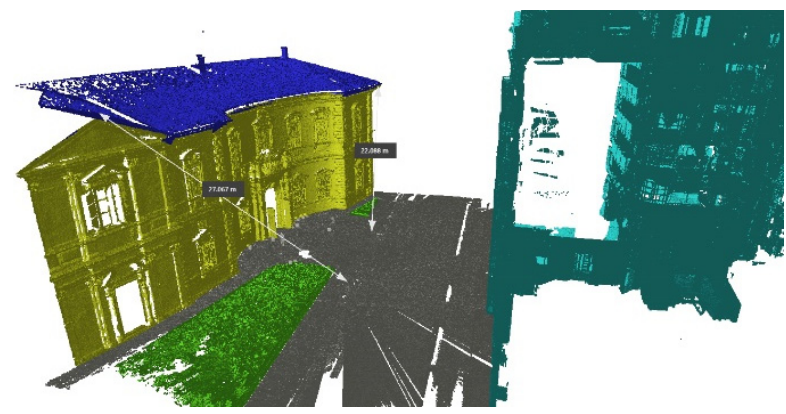

Figure 7: Laser scanner survey layout. Max. distance between the scanner head and the top of the building equal to $22 \mathrm{~m}$.

The scans were performed at the maximum resolution of $5 \mathrm{~mm} @ 10 \mathrm{~m}$ of distance, together with a precision of 4 $\mathrm{mm} @ 10 \mathrm{~m} / 7 \mathrm{~mm} @ 20 \mathrm{~m}$. The final point cloud is about 197 million points with a mean accuracy of $1 \mathrm{~cm}$, due to the distance between the head of the scanner and the farthest points at the top of the building (Fig. 8). Even if the BLK 360 has an integrated camera sensor, it was preferred to perform a fast-photogrammetric survey to get high-resolution textures to be used with the final 3D model.

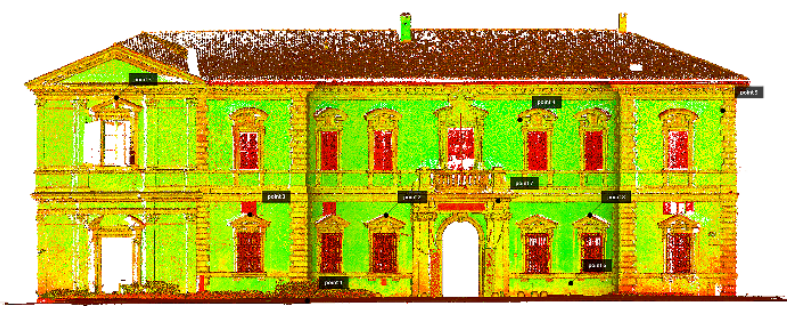

Figure 8: Laser scanner point cloud of the main façade.

\subsection{Photogrammetric survey}

The photogrammetric survey followed the CIPA recommendation adopting the $3 \times 3$ practical rules for simple photogrammetric documentation of architecture (Waldhäusl, Ogleby, Lerma, \& Georgopoulos, 2013).

As mentioned before, the photogrammetric survey was performed mainly to integrate the texture information. Even if the laser point cloud is coloured, the details are not enough to get proper textures to be used in the 3D model mapping. The images were acquired using an entry-level reflex camera, namely the Nikon D90 coupled with an 18-200 mm lens.

As suggested by the CIPA recommendation the camera was set to get the images in RAW format at the maximum resolution of 4.288 pixel * 2.848 pixels. Considering the sensor dimensions of $23,6 \mathrm{~mm} * 15,8 \mathrm{~mm}$, the pixel size of the sensor is equal to $5,5 \mu \mathrm{m}$. The photogrammetric project is composed of 142 images organised in three strips parallel to the façade plus some extra images distributed around the modern statue facing the left part of the building. The overlap of the images is more or less of $80 \%$ with some convergent images where the façade changes its shape, from linear to elliptical. These images and the farthest ones permit to have a more rigid photogrammetric block (Fig. 9).

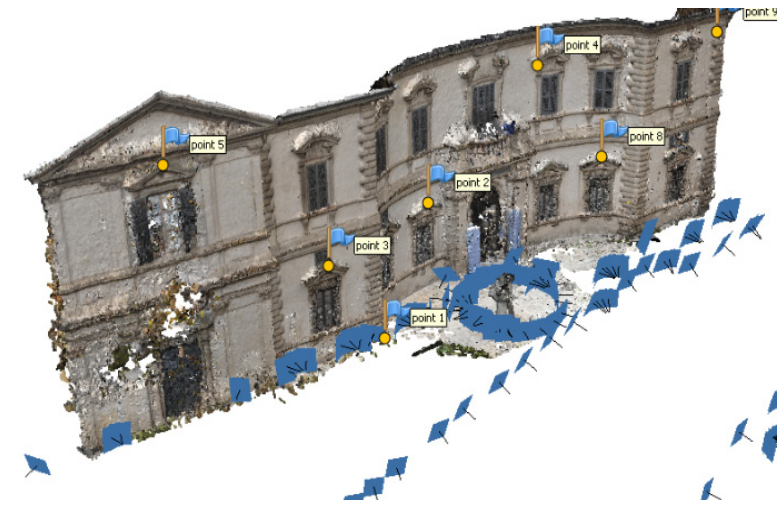

Figure 9: Photogrammetric schema acquisition. The mean distance between the images and the building equal to $10 \mathrm{~m}$.

The acquisition design described above was planned with the goal to get 3D data coherent with the TLS survey. A GSD of $3 \mathrm{~mm}$ was reached fixing with a tape the focal to $18 \mathrm{~mm}$ and maintaining a mean distance of 10 meters prof the façade.

The elaboration phase was performed using Agisoft Metashape following the proven rigid photogrammetric pipeline (Rahaman \& Champion, 2019). First, the alignment phase was concluded with all the images aligned, this suggests that the acquisition geometry was correct without missing overlaps. Also, the score of the images confirmed that all of them was suitable to be used in the following elaborations, i.e., there are no blurry, overexposed, or underexposed photos.

Then the natural points measured with the total station were placed utilizing virtual markers on the images. A mean of 20 reprojections for each measured points was considered. This phase permitted to optimise of the alignment by calculating the internal parameters of the camera and estimating the accuracy of the photogrammetric survey, which resulted in equal to $1 \mathrm{~cm}$. Moreover, constraining the position of the natural points permitted to scale and georeference of the photogrammetric survey concerning the TLS survey. This condition permitted to continue with the elaboration trusting the correctness of the measurements. The construction of the dense point cloud was performed using the "high" resolution, i.e., downscaling the images by a factor of 4 compared to the original size. Then, the dense point cloud was sampled to obtain several points as much as closer to the laser scanner point cloud. Lastly, the mesh construction and the texturing stage were performed to conclude the elaboration and to get the textures to be applied to the final 3D model.

As a final check, the laser scanner point cloud and the mesh model were imported in Geomagic Design $X$ to calculate the mesh deviation from the source point cloud 
(Mandelli, Fassi, Perfetti, \& Polari, 2017). There was no need to apply any transformation since the two 3D elaborations share the same coordinates system measured with the total station. The coloured map obtained after the comparison confirms that all the values of the distance between the mesh and the point cloud are inside the interval $\pm 1 \mathrm{~cm}$. This value confirms that the photogrammetric survey is accurate till the 1:50 rendering scale, and the texture can be used to map the 3D model that will be extracted from the laser point cloud (Fig. 10).

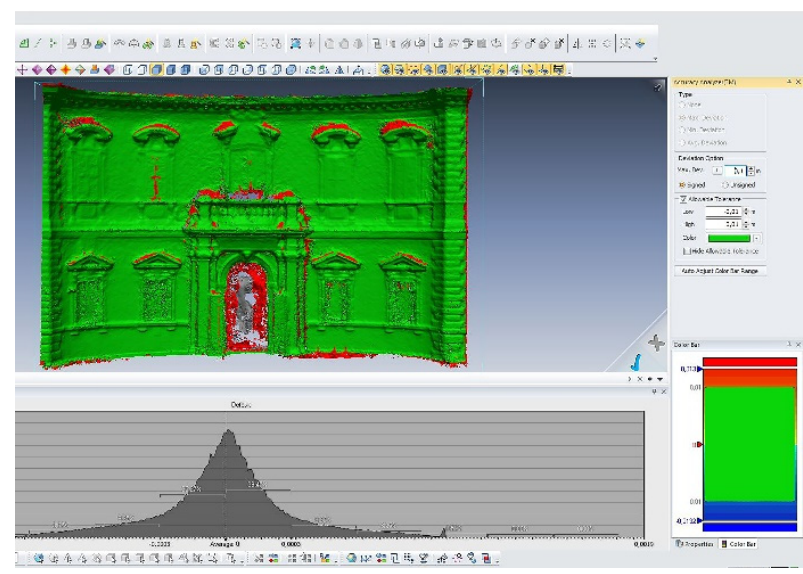

Figure 10: Cloud to mesh compute distances.

\subsection{The value of the measure: the growing need to have an appropriate basis for generating HBIM projects}

Dealing with the 3D survey of complex objects belonging to the Cultural Heritage field and their 3D representations in an HBIM system raises some questions about the value of the measure. Today it is possible to get very detailed 3D surveys, pushing the instruments (cameras a TLS) to their maximum performances. With reverse engineering software it is possible to get extremely detailed digital models interpolating almost each point of the source data (point clouds). But what is the limit? Is it useful to get these results? Are BIM software capable to manage this complexity? Firstly, the purpose of the work should be clear and consequently, it is possible to define the parameters to judge a model accurate enough to satisfy the requests. In Mandelli, Achille, Tommasi, \& Fassi (2017), had been investigated, discussed and related the plotting error $(0,2 \mathrm{~mm})$ typical of the $2 \mathrm{D}$ domain, with its corresponding value in the $3 \mathrm{D}$ domain. They were defined three parameters to evaluate if a $3 D$ model fits or not a determined representation scale. These values are the density of the raw survey data, the precision on measured reference points and the deviation between the final 3D model and the reference surveyed data. The density must be equal to or higher than the plotting error $(0,2 \mathrm{~mm})$ of the chosen representation scale. The residual error on measured points and the standard deviation must be lower compared to the representation scale. Usually, in the architectonic field and dealing with restoration activities, the representation scale adopted is 1:50. This means that, for such projects, the distance between two adjacent points, the maximum error on measured points and the standard deviation must not exceed $4 \mathrm{~mm}$. The first two parameters are intrinsic to the instruments and the design of the survey. The last one depends on the 3D model construction and the flexibility of the BIM software to adapt its modelling elements to complex shapes.
Measurements should be always consistent with the goal of the HBIM projects. Poor data coming from survey drive to models unable to meets the requirements of the work, preventing the use of them as the basis for further analyses. On the other hand, proper data collection leads to virtuous examples as described in the following paragraphs.

\section{Toward a Scan-to-HBIM process: from point clouds to accurate informative models}

In recent years, interesting studies proposed digital workflows able to manage the richness of heritage buildings through very detailed HBIM projects. Unlike digital representations of newly built buildings, HBIM was useful for investigating new types of analyses such as material analyzes (Brumana et al., 2018), construction site conservation projects (Fai, \& Rafeiro, 2014), work breakdown structures (WBS) (Putra Lim, \& Latief, 2020), mixed reality and archaeological sites (Banfi, 2020), infrastructures (Boykov, Skvortsov, \& Gurev, 2020), and finite element analysis (FEA) (Fabozzi et al., 2020). In this context, thanks to specific exchange formats have been possible to transform geometric entities such as solids, surfaces, and primitives for different types of BIM-based analyses. Consequently, the professional in charge of generating and managing the scan-to-BIM model must possess knowledge that goes far beyond those related to the construction sector of new buildings. For this reason, today the figure of architects and engineers who address these issues must also possess advanced skills in computer programming. In 2016, the Social Sciences and Humanities Research Council (SSHRC) financed the research activity of any authors through the New Paradigm/New Tools for Architectural Heritage training program (NPNT, 2020) at Carleton Immersive Media Studio (CIMS) research centres Lab - Carleton University in Ottawa and at Autodesk Research Toronto, Ontario (Canada). Thanks to this collaboration, it was possible to undertake a line of IT development capable of proposing new solutions for the management of built heritage in the following years. As shown in the next paragraphs, through the case study of the Senate building in Milan, it was possible to identify the GOGs, LOls, exchange formats, platforms, and APIs useful for improving the Scan-toHBIM process, passing from simple points (point clouds) to information models capable of going far beyond simple two-dimensional representations.

\subsection{The value of scan-to-BIM process: application of the Grades of Generation (GOG) and descriptive geometry for heritage building}

After one year of experience in the CIMS lab and Autodesk Research Toronto, one of the authors proposed new scan-to-BIM modelling requirements, known as grades of generation (GOG) (Banfi, 2017). GOGs are based on a geometric representation of point clouds capable of connecting various types of information. It is known that BIM platforms were developed for the management of new buildings. This aspect nowadays leads BIM users to deal with a limited number of commands (GOG 1 to 8 ), designed for buildings composed of regular objects compared to those that characterize heritage buildings. For this reason, two new GOGs (9 \& 10) have been defined as able to exploit 
NURBS algorithms for the generation of complex models, and consequently, once imported into Autodesk Revit, automatically generate HBIM objects with high grades of accuracy (GOA). On the other hand, however, it should be noted that one of the main difficulties of the scan-toBIM process is the simultaneous use of different modelling software. In fact, applications have many inequalities such as the constructive logic of the model, interface, primitives, modelling tools and exchange formats. For this reason, this study compares these limits related to these software differences, which in many cases, despite having the same input data (point clouds), can generate different outputs, especially in the field of HBIM. Consequently, thanks to the application of different GOGs it was possible to carry out the case study of the façade of the Senate building which is characterized by many complex historical architectural elements. Besides, as shown in Fig. 11, GOGs made it possible to identify the exchange formats necessary to improve the dialogue between NURBS modelling applications such as McNeel Rhinoceros and BIM software such as Revit and Archicad.

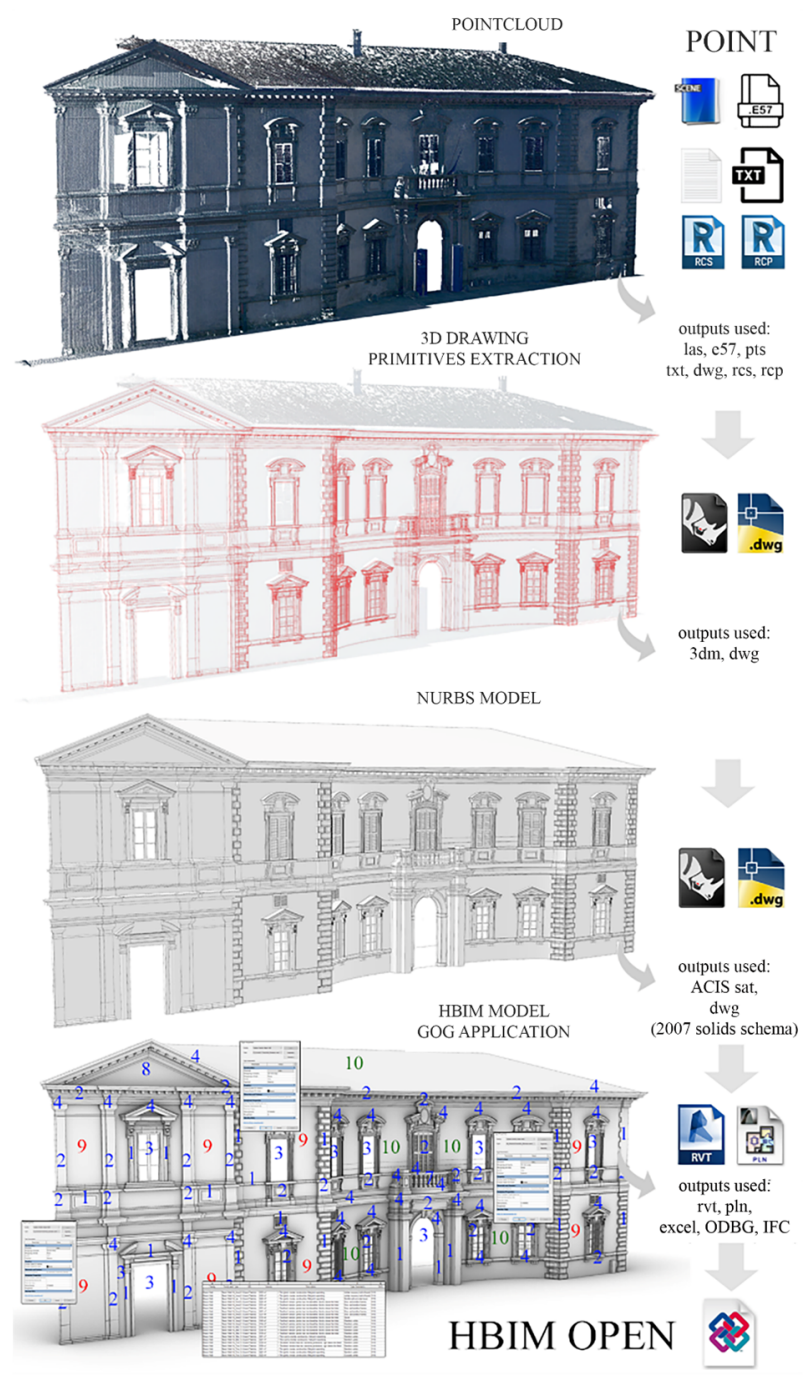

Figure 11: Open HBIM-based workflow for heritage buildings: from simple points to complex models. The exchange formats used for the model generation and ten Grades of Generations (GOG) applied to the scan-to-BIM steps.
In particular, the proposed research approach is based on the following steps and exchange formats:

- $\quad$ Laser scanning outputs used: las, e57, pts;

- Photogrammetry outputs used: pts, jpg, png;

- AutoCad and Recap Pro outputs used: dxf, dwg, rcs, rcp;

- NURBS model generation outputs used: $3 \mathrm{dm}$, dwg (2007 solids schema), ACIS sat;

- HBIM generations outputs used: rvt, ifc, excel, ODBC.

Through this selection, it was possible to transform simple points into complex HBIM objects capable of communicating different types of information in an open language. It was found that the format and the best scheme to be able to dialogue between NURBS modellers and BIM software is the DWG format. It should, however, be emphasized that the DWG format, in turn, must be based on a specific export scheme that can transform primitives, surfaces and solids into entities recognizable by the BIM application. The final step consists of the automatic or semiautomatic transformation of geometric assets into BIM objects capable of being linked to alphanumeric information and new HBIM parameters. Figure 12 shows the export scheme used to transform automatic NURBS models into entities that can be recognized by BIM applications such as Autodesk Revit and Graphisoft Archicad.

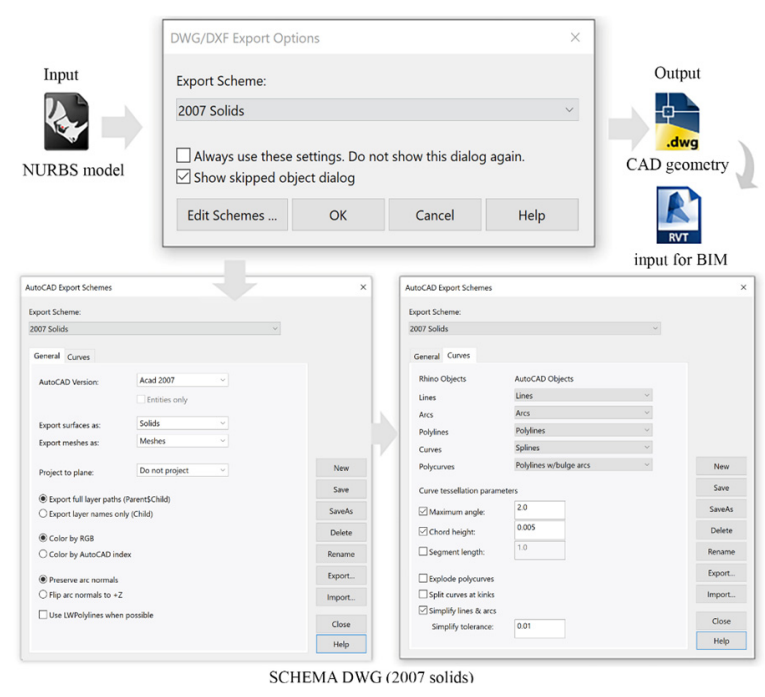

Figure 12: Open HBIM-based workflow is based on the schema definition of the DWG format.

\subsection{Information mapping: semantic enrichment of the model and the development of new HBIM parameters}

The 80 s and 90 s were characterized by a sudden change in the main techniques of representation. Mainly Autodesk with its flagship software (AutoCad) has allowed professionals to reduce exponentially the time dedicated to the realization of drawings able to represent buildings following ISO and UNI standards, passing from manual drawing (on paper) to digital one. On the other hand, in recent years we have seen how BIM has made it possible to link parameters and information to 2D and 3D representations. Thanks to a two-way relationship between information and objects created, it is possible to 
increase the communicative value of each element. Where before in the CAD software we had simple lines, now in the BIM platforms we have parametric elements corresponding to the architectural, structural, and mechanical, electrical, and plumbing (MEP) components of the buildings. In the domain of built heritage, GOGs and the scan-to-BIM process, in general, made it possible to generate unique HBIM objects such as vaults, walls with variable sections, damaged walls and many other elements capable of communicating new information and parameters, unlike new buildings. Therefore, to support the information value of each element, parameters capable of accommodating alphanumeric values have been implemented for the façade of the Senate building. Figure 13 shows the process applied to develop new parameters for different types of HBIM objects to communicate information of a historical, material, physical and mechanical nature. In addition to these types of information, BIM parameters have been developed which in turn can collect the values deriving from the analysis of the automatic verification system (AVS), the grade of accuracy (GOA), standard deviation and GOG used. Consequently, through schedules, databases linked to the objects, it was possible to communicate to the future users the reliability of the model also in numerical terms.

\section{Information sharing and the Common data environment (CDE) of the research project: novel strategies to share digital HBIM models and information}

As briefly described in the previous paragraphs, one of the main objectives of this approach is to identify exchange formats and methods capable of increasing the communicative value of digital models for historic buildings and favouring the sharing of different types of information connected to the model at the same time. To do this, it was necessary to investigate new computer development languages and test many shared application programming interfaces (APIs) through the main online repositories such as Autodesk Revit API and Autodesk Forge. Thanks to the project "HOMeBIM liveAPP: Development of a multi-user Live APP of $4 D$ virtual reality for the improvement of comfort-efficiency costs, from a cloud platform that controls the BIM-sensor flow over time - ID 379270 funded by Regione Lombardia" - it was possible to develop a BIM-based cloud platform able to welcome and share any type of HBIM model and format. Thanks to the use of the IFC it has been possible to convert the information connected to them as well as the BIM objects, such as the parameters described in the previous paragraph, the numerical values associated with the physical and mechanical features and the descriptive fields created to deepen the material and historical characteristics of historical elements at the same time. Figure 14 shows the developed interface and how the geometric model is closely linked to functions capable of communicating alphanumeric contents. Therefore, it was possible to implement the information sharing phase which for the most part is characterized by a serious loss of information between the various users involved in the process. Finally, thanks to the sharing of the model in the platform, all users involved (experts and non-experts) can investigate the various levels of information and in turn, share any type of format.
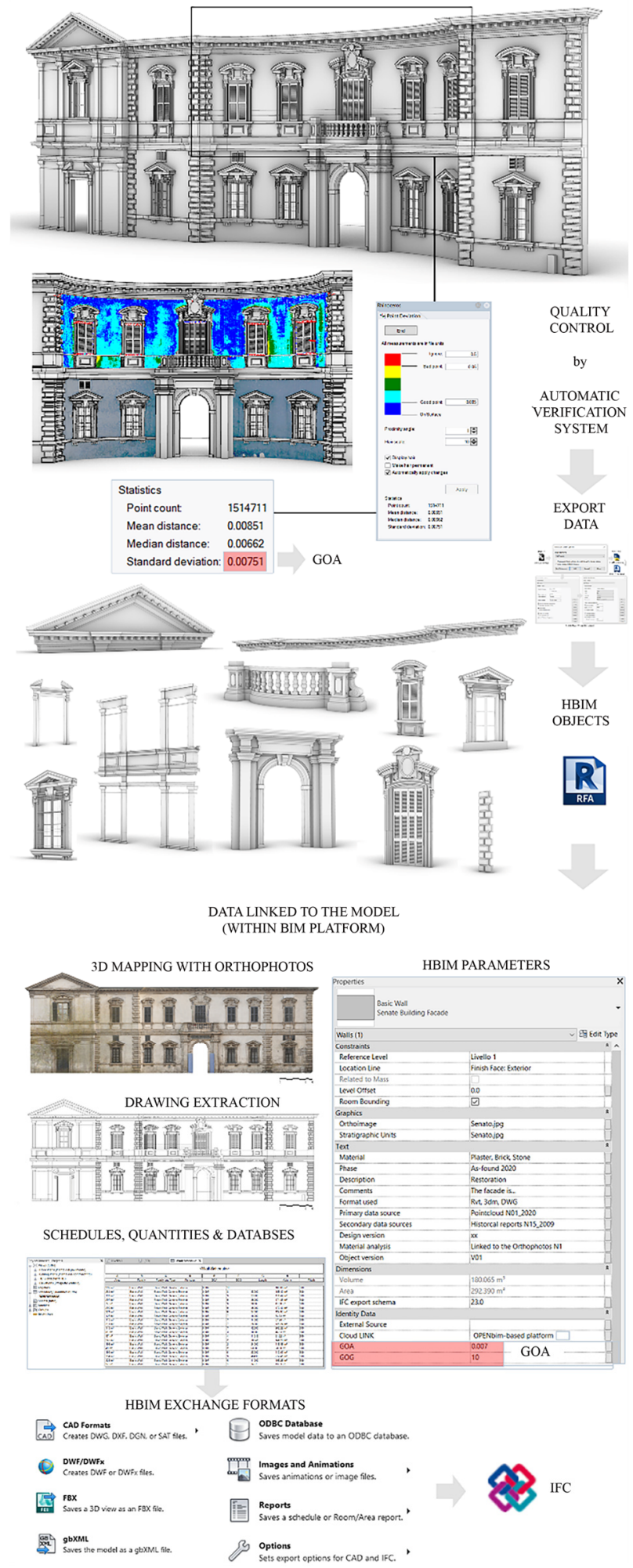

Figure 13: From 2D drawings and historical objects to BIM parameters, schedules, and databases for heritage buildings.

\section{Discussion and Results: from simple points to open exchange formats and vice-versa}

As demonstrated in the previous paragraphs, each element that makes up a complex HBIM model can achieve high LODs and LOIs at the same time. Thanks to the bidirectional relationship between object and 
information, for the case study of the Senate building, new information fields have been implemented.

Unlike pure modellers, it is known that BIM applications are used to involve as much as possible many experts, operating in turn in different application fields and with different software. For this reason, according to the project objectives, Figure 15 also shows the identification of descriptive fields developed for heritage elements, which can accommodate and connect external data sources, with the goal of expanding the information value of all the elements investigated at a geometric level.

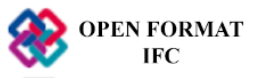

OPEN BIM BASED CLOUD PLATFORM

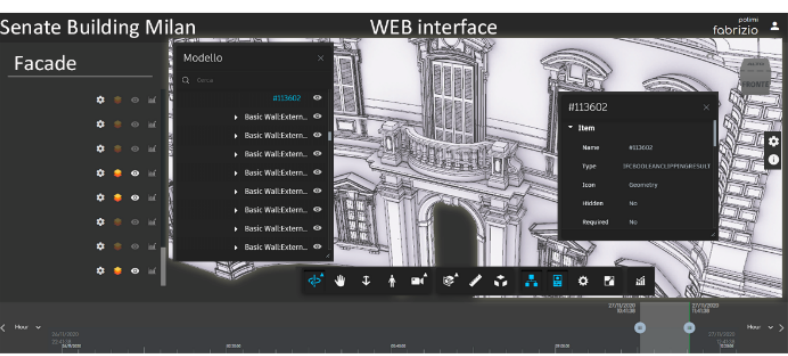

Accepted File Formats for Uploads in cloud (in addition to 3D formats)

Media file formats

3G2, 3GP, ASF, AVX, AVI, BMP, DIVX, DV, DVI, F4V, FLI, FLC, FLV, GIF, JPE, JPEG, JPG, MOV, MOVIE, MP4, MPE, MPG, MPEG, MPV2, OGG, PNG, PPM, QT, RM, TIF, TIFF, WEBM, WMV

Office file formats

CSV, DOC, DOCM, DOCX, ODP, ODS, ODT, PDF, PS, POT, POTM, POTX, PPT, PPTX, RTF, TXT, XLS, XLSX

Figure 14: The BIM-based cloud platform able to share any types of formats.

\section{IMPORT/EXPORT POINTCLOUD FORMATS}

Faro, Scene:

Import: $\mathrm{XYZ}, \mathrm{CVS}, \mathrm{COR}$

Export: E57

Autodesk, ReCap:

Import: E57, ISPROJ, LAS

PTS, DXF, DWG

Export: RCS, RCP, PCG, PTS, E57, DXF, DWG Leica, Cyclone:

Import: E57, LSPROJ, BLK

Export: E57,RCP, RCS

Agisoft Metashape

Import: JPG, PNG, E57, PTS

Export: E57, PTS

3D EXCHANGE FORMATS

3DM, DWG, FBX, IFC, RVT

Figure 15: The selection of exchange formats for the proposed scan-to-HBIM process. IFC is considered the result to share informative models in an open way.

It was found that the modelling and the descriptive geometry made it possible to reach different LODs depending on the project needs. As regards the LOls, it was found that they are strictly linked to the generation of a three-dimensional element: the information can be linked if a "container" has previously been created. In this case and in the field of BIM in general, the ability to accommodate different types of information depends solely on "how" the professional in charge of creating and managing the model digitally enables all these fields (BIM parameters). For this reason, the value of the measure and the descriptive geometry in support of the scan-toBIM process are crucial and certainly not left to chance.

In this context, open formats are reachable and usable for open BIM cloud platforms only if objects have previously been created in BIM logic. The IFC format must be considered as one more possibility to share information related to geometric elements which in turn correspond to architectural, structural, and plant elements. For the heritage documentation sector, on the other hand, elements such as vaults, walls, arches, capitals, and classical columns cannot be represented by IFC categories aimed at historic buildings. For this reason, the following study proposes a workflow capable of transforming historical objects both in proprietary and open formats such as IFC according to the project needs.

In the specific case of the Senate building, the wall BIM family has made it possible to maintain the bidirectional relationship between IFC formats (easily usable even by non-experts) and BIM software. Besides, it should be emphasized that in recent years the exchange formats and schemes based on CAD formats have also been improved. It has been found that working simultaneously in both McNeel Rhinoceros and Autodesk Revit through GOG 9 \& 10 allows experts to complete complex models also from an informative point of view. Consequently, it was considered essential for the research case study to also test the proposed workflow in reverse to evaluate pros and cons in a more digital and IT perspective.

In fact, the reverse process (from information to points) based on three main steps, is immediately blocked by the IFC format. Once the BIM model has been exported to IFC, its geometries are frozen and once re-imported into the BIM platforms it is no longer possible to consider them as real parametric objects.

By bypassing this aspect and moving backwards (from BIM platforms to NURBS modellers), we found the "new" possibility of migrating BIM objects by categories to pure modellers such as Autodesk 3D Studio Max and McNeel Rhinoceros. In the DWG format (ACIS sat scheme) it is possible to switch from Autodesk Revit to McNeel Rhinoceros object categories such as walls, floors, windows, roofs, etc. The latter, once imported into the pure modeller, is recognized in layers, and automatically renamed in specific categories.

Finally, again in a geometric context, the transition from NURBS models to points is based on the extraction of the latter directly from solids, poly-surfaces, surfaces, and curves. Thanks to NURBS algorithms it is possible to automatically recover the primitives from which the whole process proposed this study started.

\section{Conclusion}

When we talk about interoperability in the field of HBIM it is essential to consider and use the exchange formats (proprietary and open) appropriately. Thanks to specific 3D schemes and model transformations it has been possible to improve the communication between software and users. When the Cultural Heritage sector has become digital and computable, the world of making as-found drawing and 3D architectural representations are changed forever. In recent years we are witnesses a leap 
forward driven by advanced digital tools and maturing methods that are opening new sectors and disciplines based on the use of detailed HBIM models.

For this reason, this article proposes a digital workflow aimed at transforming simple points (3D survey data) into digital contents (informative models), which in turn are connected to models based on a scan-to-BIM process. In this context, the authors investigated and applied a real case study that has characterized the history and culture of the city of Milan, different techniques and methods of $3 \mathrm{D}$ survey and digital representation to achieve high levels of information sharing.

Visiting the frontlines of development in the heritage documentation field, authors combine disciplines such as geomatics, 3D modelling, BIM, and digital clouds to improve the level of details (LOD), and the grade of accuracy (GOA) of heritage buildings.

Accordingly, the values of measurement and representation have been investigated and applied to architectural and complex elements both from a geometric and descriptive point of view.
BIM parameters have been developed to improve the ability of each HBIM objects that made up the buildings, communicating material and historical information of each individual element created. Preservation and restoration projects can now benefit from these new tools and exchange format to improve the design, restoration, preservation, maintenance, and many other forms of activities aimed to support the life cycle of heritage buildings openly and sustainably.

\section{Acknowledgements}

The research leading to the results of this paper is partially funded by Regione Lombardia - Bando "Smart Living: integrazione fra produzione servizi e tecnologia nella filiera costruzioni-legno-arredo-casa" approvato con d.d.u.o. n.11672 del 15 novembre 2016 per la presentazione di progetti di sviluppo sperimentale e innovazione (S\&I) a favore della filiera dello "Smart Living" e nell'ambito del progetto "HOMeBIM liveAPP: Sviluppo di una Live APP multi-utente della realtà virtuale abitativa 4D per il miglioramento di comfort-efficienza-costi, da una piattaforma cloud che controlla nel tempo il flusso BIMsensori - ID 379270".

\section{References}

Banfi, F. (2017). BIM orientation: grades of generation and information for different type of analysis and management process. International Archives of the Photogrammetry, Remote Sensing and Spatial Information Sciences, 42(2/W5), 57-64. https://10.5194/isprs-archives-XLII-2-W5-57-2017

Banfi, F. (2020). HBIM, 3D drawing and virtual reality for archaeological sites and ancient ruins. Virtual Archaeology Review, 11(23), 16-33. https://doi.org/10.4995/var.2020.12416

Boykov, V. N., Skvortsov, A. V., \& Gurev, V. A. (2020). InfraBIM Open paradigm as the driver of informatization of the road sector in Russia. In IOP Conference Series: Materials Science and Engineering, 832, 012045. IOP Publishing.

Brumana, R., Della Torre, S., Previtali, M., Barazzetti, L., Cantini, L., Oreni, D., \& Banfi, F. (2018). Generative HBIM modelling to embody complexity (LOD, LOG, LOA, LOI): surveying, preservation, site intervention-the Basilica di Collemaggio (L’Aquila). Applied geomatics, 10(4), 545-567. https://doi.org/10.1007/s12518-018-0233-3

Cabrelles, M., Blanco-Pons, S., Carrión-Ruiz, B., \& Lerma, J. L. (2018). From Multispectral 3D Recording and Documentation to Development of Mobile Apps for Dissemination of Cultural Heritage. In T. E. Levy \& I. W. N. Jones (Eds.), Cyber-Archaeology and Grand Narratives: Digital Technology and Deep-Time Perspectives on Culture Change in the Middle East (pp. 67-90). https://doi.org/10.1007/978-3-319-65693-9

Fabozzi, S., Cipolletta, G., Capano, E., Asprone, D., Dell'Acqua, G., \& Bilotta, E. (2020). BIM-FEM interoperability for the modelling of a traditional excavated tunnel. Tunnels and Underground Cities: Engineering and Innovation Meet Archaeology, Architecture and Art: Volume 3: Geological and Geotechnical Knowledge and Requirements for Project Implementation, 785.

Tucci, G., Conti, A., Fiorini, L., Corongiu, M., Valdambrini, N., \& Matta, C. (2019). M-BIM: a new tool for the Galleria dell'Accademia di Firenze. Virtual Archaeology Review, 10(21), 40-55. https://doi.org/10.4995/var.2019.11943

Onida, N. (1997). Architetture milanesi. Collegio Elvetico, centro per l'architettura di Milano.

Villa, P. (ND). Technical report. Milano ex Collegio Elvetico Palazzo del Senato Archivio di Stato Restauro conservativo eseguito sull'apparato decorativo della "sala degli affreschi" ed altri ambienti al primo piano 2009/2012. Milano nei cantieri dell'arte. Available at: http://www2.milanoneicantieridellarte.it/cms/wpcontent/files_flutter/1334326361Reltec.pdf

Achille, C., Fassi, F., Mandelli, A., Perfetti, L., Rechichi, F., \& Teruggi, S. (2019). From a Traditional to a Digital Site: 20082019. The History of Milan Cathedral Surveys. Digital Transformation of the Design, Construction and Management Processes of the Built Environment. Springer International Publishing, 331-341.

buildingSMART. (2020). buildingSMART - The Home of BIM. Retrieved March 15, 2021, from https://www.buildingsmart.org

Colucci, E., De Ruvo, V., Lingua, A., Matrone, F., \& Rizzo, G. (2020). HBIM-GIS Integration: From IFC to CityGML Standard for Damaged Cultural Heritage in a Multiscale 3D GIS. Applied Sciences, 10(4), 1356. https://doi.org/10.3390/app10041356 
Grussenmeyer, P., Hanke, K., \& Streilein, A. (2002). Architectural photogrammetry. In M. KASSER and Y. EGELS, Taylor \& Francis (Eds.), Digital Photogrammetry (pp. 300-339)

Fai, S., \& Rafeiro, J. (2014). Establishing an appropriate level of detail (LoD) for a building information model (BIM)-West Block, Parliament Hill, Ottawa, Canada. ISPRS Annals of the Photogrammetry, Remote Sensing and Spatial Information Sciences, 2(5), 123. https://doi:10.5194/isprsannals-II-5-123-2014

Goulding, J. S., Rahimian, F. P., \& Wang, X. (2014). Virtual reality-based cloud BIM platform for integrated AEC projects. Journal of Information Technology in Construction, 19, 308-325.

Luedy, L., Couto, P., Silva, M. J. F., \& Hormigo, J. (2020). Information Requirements to BIM Models. In Sustainability and Automation in Smart Constructions (pp. 29-35). Springer, Cham.

Mandelli, A., Achille, C., Tommasi, C., \& Fassi, F. (2017). Integration of 3D models and diagnostic analyses through a conservation-oriented information system. Int. Arch. Photogramm. Remote Sens. Spatial Inf. Sci., XLII-2/W5, 497504. https://doi.org/10.5194/isprs-archives-XLII-2-W5-497-2017

Mandelli, A., Fassi, F., Perfetti, L., \& Polari, C. (2017). Testing different survey techniques to model architectonic narrow spaces. Int. Arch. Photogramm. Remote Sens. Spatial Inf. Sci., XLII-2/W5, 505-511, 2017. https://doi.org/10.5194/isprs-archives-XLII-2-W5-505-2017

NPNT. (2020). New Paradigm / New Tools for Architectural Heritage in Canada. March 15, 2021, from http://npnt.ca/\#/home

Putra Lim, A. W., \& Latief, Y. (2020). The Development of Safety Plan Using Work Breakdown Structure (WBS) for Building Information Modelling (BIM)-Based Building Structure Work. Journal of Computational and Theoretical Nanoscience, 17(2-3), 1402-1413. https://doi.org/10.1166/jctn.2020.8818

Rahaman, H., \& Champion, E. (2019). To 3D or Not 3D: Choosing a Photogrammetry Workflow for Cultural Heritage Groups. Heritage, 2, 1835-1851. https://doi.org/10.3390/heritage2030112

Tommasi, C., \& Achille, C. (2017). Interoperability matter: levels of data sharing, starting from a 3d information modelling. Int. Arch. Photogramm. Remote Sens. Spatial Inf. Sci., XLII-2/W3, 623-630, 2017. https://doi.org/10.5194/isprsarchives-XLII-2-W3-623-2017

Tommasi, C., Achille, C., \& Fassi, F. (2016). From point cloud to BIM: a modelling challenge in the cultural heritage field. Int. Arch. Photogramm. Remote Sens. Spatial Inf. Sci., XLI-B5, 429-436, 2016. https://doi.org/10.5194/isprsarchives-XLI-B5-429-2016

Waldhäusl, P., Ogleby, C. L., Lerma, J. L., \& Georgopoulos, A. (2013). 3 x 3 Rules for Simple Photogrammetric Documentation of Architecture. Available at: https://www.cipaheritagedocumentation.org/wpcontent/uploads/2017/02/CIPA_3x3_rules_20131018.pdf 